\title{
Development and Evaluation of Rail Steel Grade for Damage Restraint to High Rail in Curve Sections
}

\author{
Yoshikazu KANEMATSU \\ Motohide MATSUI \\ Frictional Materials Laboratory, Materials Technology Division \\ Masahiro TSUIJIE \\ Track Dynamics Laboratory, Railway Dynamics Division
}

\begin{abstract}
The head hardened rail (HH340 rail, 340HB) which is harder than the normal rail (AS rolled rail, 270HB) is used as the high rail in curve sections to reduce the wear. The HH340 rail shows a wear resistantce effect. However, in late years, the Gauge Corner Cracking occurs to the HH340 rail of the high rail in curve sections with a curve radius of $600 \mathrm{~m}$ to 800 $m$. Therefore, authors developed a new type head hardened rail in this study for the purpose of the prevention of rail failure and the reduction of track maintenance.
\end{abstract}

Keywords: rail steel grade, head hardened rail, gauge corner cracking, wear

\section{Introduction}

When a train passes a curve, the wear of the high rail is progressed by the lateral force and the sliding contact of the wheel flange. In such tracks as are intended for the light axle loads (approximately 10 tons) of Japanese conventional lines, the head hardened rail (HH340 rail, $340 \mathrm{HB}$ ) which is harder than the normal rail (as rolled rail, 270HB) is used for the high rail in the curve sections to reduce the wear. These rails are prescribed by Japanese Industrial Standards (JIS) [1].

The HH340 rail shows a wear resistantce effect. However, in late years, rail failure occurs to the HH340 rail of the high rail in curve sections with a curve radius of $600 \mathrm{~m}$ to $800 \mathrm{~m}$ (see Fig. 1). This failure is termed as Gauge Corner Clacking (GCC) in Japan. The GCC is one of the rail failures due to rolling contact fatigue, which often results in a rail break. Compared with the head checks shown in Fig. 2, the morphology of the GCC (Fig. 1) is usually different from that of the head checks. This is thought to be attributable to their different damage mechanisms. For this reason, the demand for the modification of the HH340 rail has arisen to reduce the risk of the GCC in the curve sections especially with a curve radius of 600 to $800 \mathrm{~m}$.

The researches on the proper selection of the steel grade of the rail in the curve sections have been carried out

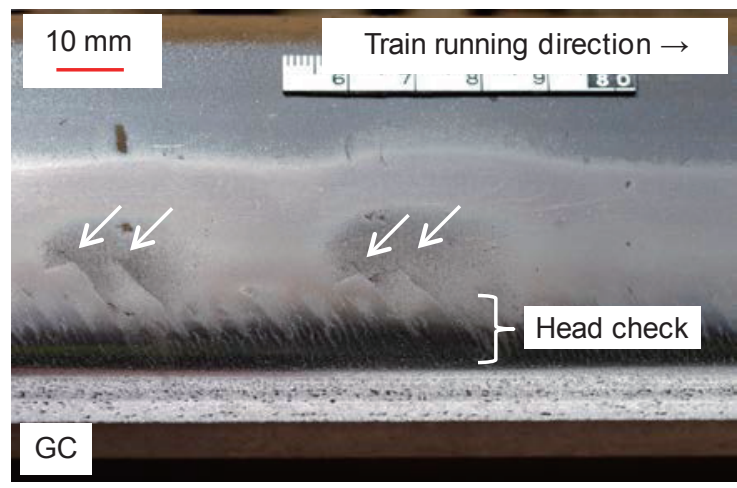

Fig. 1 Gauge corner crack (GCC)

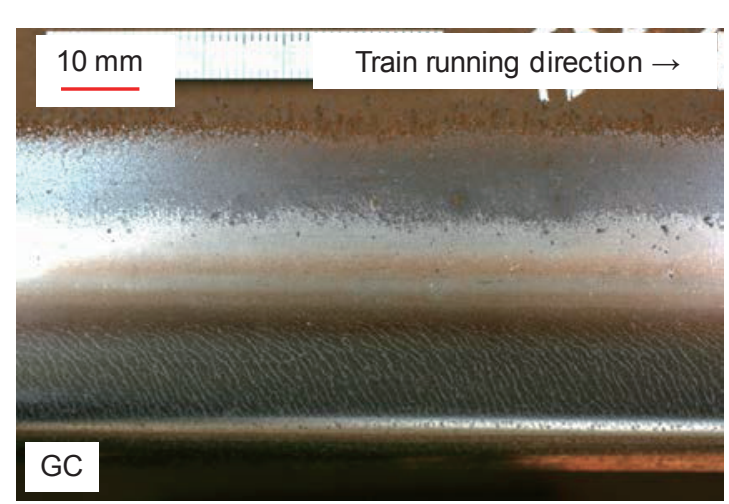

Fig. 2 Head check

so far [2-4]. The policy on the selection is derived from the relationship between the wear and the damage of the inservice rails in the curve sections with the various curve radii. However, all the studies deal with heavy haul railways with a focus on the head checks.

Therefore, the authors have developed new types of head hardened rails for the purpose of preventing the GCC and reducing track maintenance work. In addition the authors show the interim result of the continuing examinations on their installation.

\section{The damage of the head hardened rail}

\subsection{Morphology of the damage}

The damage often occurs in the gauge corner because the HH340 rail is used for the high rail in curve sections. Regarding the damage of the high rail in curve sections, it is classified roughly into the head checks and the GCC (see Fig. 1 and Fig. 2).

The head checks are short cracks generated at the gauge corner of the high rail. It has a certain angle with the train running direction. Generally, the head checks stop growing at a certain depth. On the other hand, the 
GCC tends to be formed at positions closer to the rail center in the gauge corner, and progresses to a horizontal split head and transverse cracking, and finally results in rail failure. In addition, the GCC is often formed in the neighborhood of the head checks. Furthermore, the detection of transverse cracking by a rail flaw detection car is difficult because the GCC often occurs in clusters, and horizontal split head adjacent to each other overlap and interrupt the detection. Therefore, the reduction of the GCC is demanded especially out of safety concern.

\subsection{Characteristics of the GCC}

Authors carried out the fracture analysis of the HH340 rails which were broken by the GCC, and summarized the characteristics of the rail damage due to the GCC. Table 1 shows the specifications of these rails such as the curve radius and the accumulative passage tonnage. These rails were used for the high rail in curve sections with a radius of $800 \mathrm{~m}$. Figure 3 shows the top surface of the no. 3 rail. The head check are observable in the gauge corner, and chevron-shaped cracks of the corners characterize the GCC occurring at the gauge corner.

Figure 3 schematically shows the process of the crack progress. From this figure, the following matters are guessed. At first a rolling contact fatigue (RCF) crack was initiated as the GCC at the gauge corner in the neighborhood of the head checks. Then, a fatigue crack branched from the horizontal split head in such a way as to from transverse cracking progressed in the rail bottom direction. And the transverse cracking suddenly progressed and reached rail failure. The form of the progress of such a crack is similar to that of the squat damage.

Magnetic Particle Testing was carried out to confirm the state of the crack propagation. The section of the center of the rail width at the break position of the No.3 rail and the section in the longitudinal direction across the break position of the No.3 rail were inspected. Figure 4 shows the test result. Transverse cracking was not observed at any place other than the break position, but a horizontal split head was observed at a depth of 5 to 8 $\mathrm{mm}$ from the running surface over the entire length of the No.3 rail. In addition, layered horizontal split heads are confirmed, and the progress of the crack assumes a complicated aspect.

The form of the progress of the crack of the rail which reached rail failure by the GCC is different from that by the squat in the following points.

(a) The depth of the progress of the horizontal split head is large (approximately $5 \mathrm{~mm}-8 \mathrm{~mm}$ ).

(b) The horizontal split heads are formed intermittently
Table 1 Specifications of the rail investigated

\begin{tabular}{|c|c|c|c|c|}
\hline No. & Rail grade & $\begin{array}{c}\text { Curve radius } \\
(\mathrm{m})\end{array}$ & $\begin{array}{c}\text { Passing tonnage } \\
(\mathrm{MGT})\end{array}$ & $\begin{array}{c}\text { Continuous welded rail/ } \\
\text { unit length rail }\end{array}$ \\
\hline 1 & HH340 & 800 & 280 & CWR \\
\hline 2 & HH340 & 800 & 280 & CWR \\
\hline 3 & HH340 & 800 & 230 & CWR \\
\hline 4 & HH340 & 800 & 372 & CWR \\
\hline
\end{tabular}

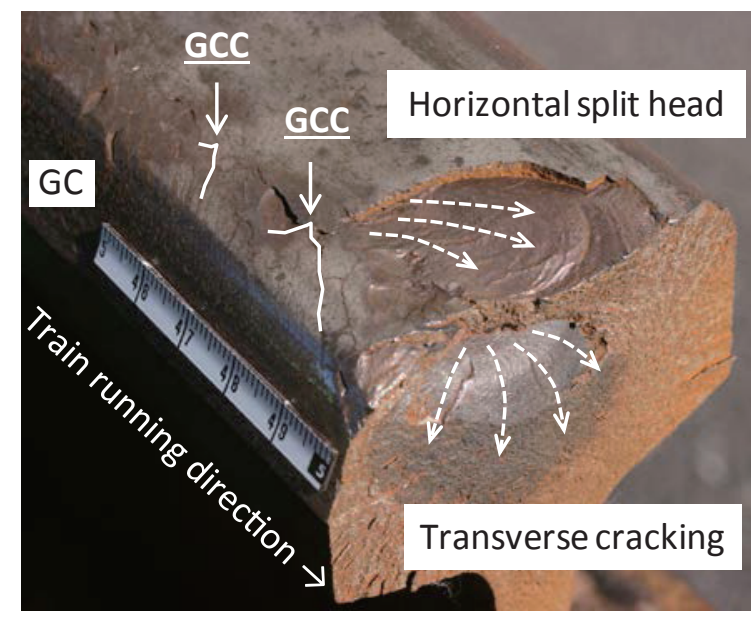

Fig. 3 The appearance of a failure rail by the GCC

and layered. The area where the transverse cracking progresses tends to be at the gauge corner, not at the center of the rail width. Therefore, it is difficult to detect a crack precisely by ultrasonic testing from the top surface of the railhead.

(c) In the GCC, the area where the transverse cracking progresses is narrow and the angle of the progress of the transverse cracking is large. The depth of the positions where the transverse cracking initiates the brittle fracture does not vary from one position to another as far as the investigations conducted on the rails with the GCC are concerned. It is shallow, i.e., about $2 / 3$ that of the squat. Therefore, it is thought that the time before reaching rail failure is shorter than that the squat in the straight line section takes.

\section{The trend of the damage occurring to the high rail in curve sections}

Authors gathered the data of the rail flaw detection car from Japanese railway companies in order to understand the trend of the damage occurring to the high rail in curve
Running surface

\section{$\leftarrow$ Train running direction}

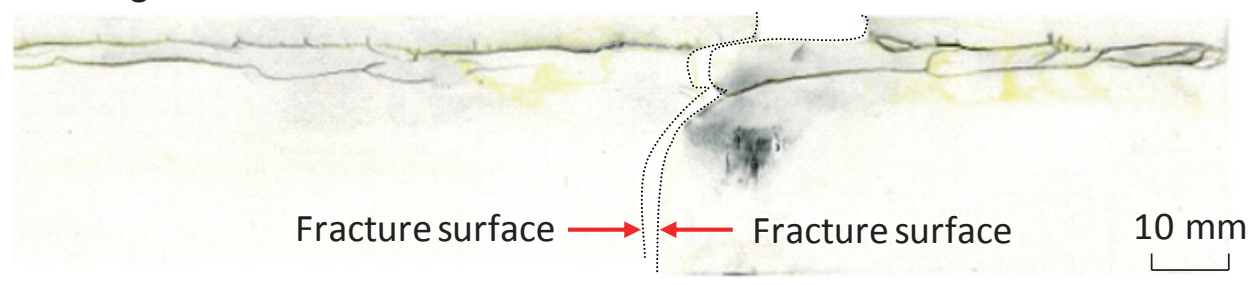

Fig. 4 The progress of the horizontal split head by magnetic particle testing 
sections through statistical analysis. The target curves selected for the statistical analysis are more than $100 \mathrm{~m}$ in length and more than 150MGT in passing tonnage, and neither ground nor lubricated.

Figure 5 and Fig. 6 show the number of curves to fulfill the above conditions. As for the specifications of the curve that are used by this analysis, a curve radius of 600 accounted a lot. In addition, the accumulative passage tonnage less than 300 million tons accounted for the most. Figure 7 shows the damage occurrence rate of the head hardened rail and the as rolled rail depending on the radius of curves. As an overall tendency, the damage occurrence rate of the as rolled rail was lower than that of the head hardened rail. Particularly at a curve of $600 \mathrm{~m}$ in radius, the as rolled rail had $18 \%$, whereas the head hardened rail had $57 \%$. This tendency is attributable to conditions in which the wear of the As rolled rail tends to be promoted due to its low hardness, while the RCF can be prevented from accumulating.

In addition, Takikawa reported the rate of the track length with the head checks to the total curved track length [5]. The head checks include all kinds of damage to the high rail in the curve section, and the GCC, too. It is reported that in curve sections with a radius of $600 \mathrm{~m}$ to $700 \mathrm{~m}$ where the $\mathrm{HH} 340$ rail was installed, the rate of the track length with the head checks is high. Judging from the above-mentioned description, It is possible that the GCC occurrence is controlled by the rail steel grade (strength, hardness, wear rate, etc.). Generally, in Japan, the rail steel grade is selectable from two kinds, namely, the as rolled rail and the HH340 rail. Therefore, rail operators will choose the as rolled rail because there is no room for the selection except the as rolled rail to reduce the GCC. However, since the as rolled rail reaches the wear limit rather quickly, it is expected that the rail renewal occurs at short intervals. Therefore, authors developed new types of head hardened rails and carried out an installation examination to confirm their GCC - resistantce characteristics.

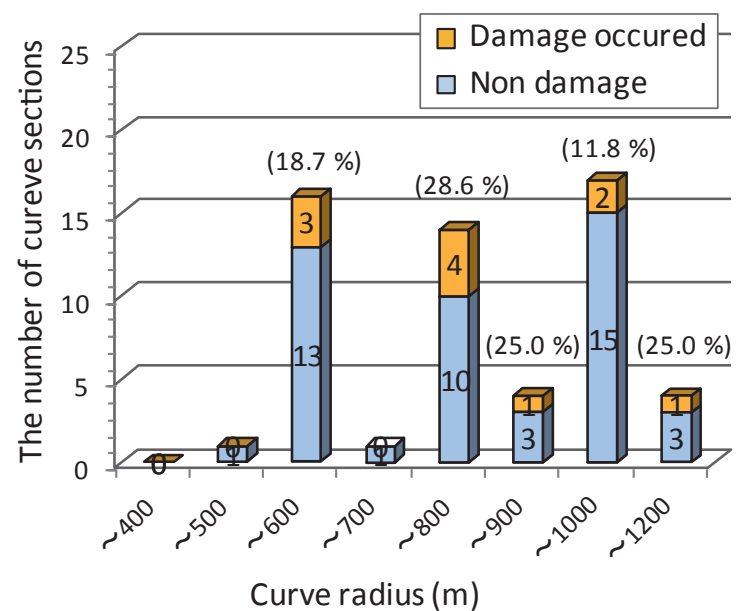

(a) As rolled rail

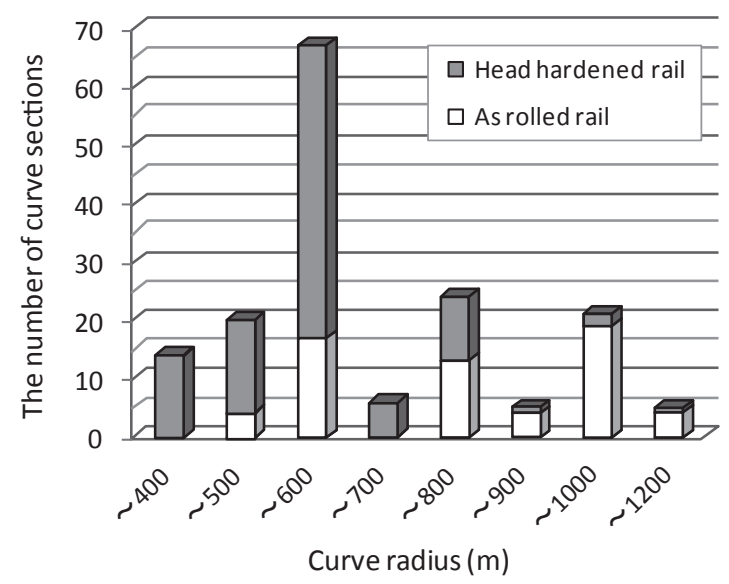

Fig. 5 The number of curve sections (Curve radius)

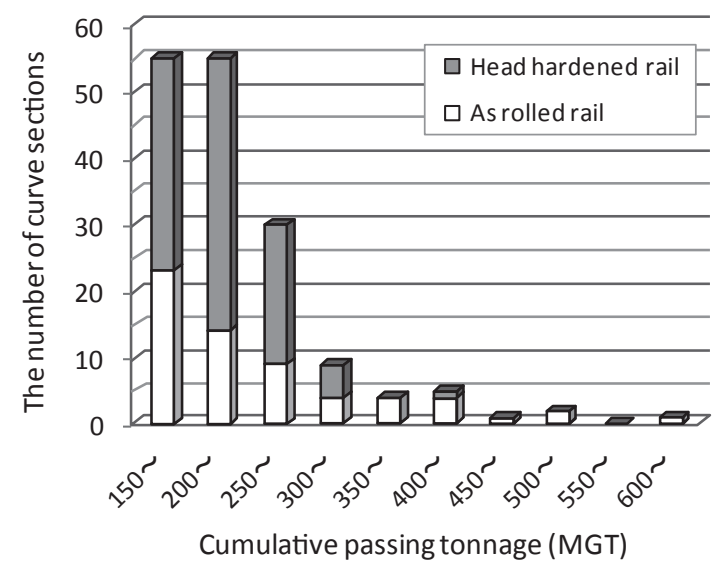

Fig. 6 The number of curve sections (Cumulative passing tonnage)

\section{The new types of head hardened rails}

The new types of head hardened rails cover four rail steel grades under two types of concepts. Three rails are produced according to the first concept. There are three

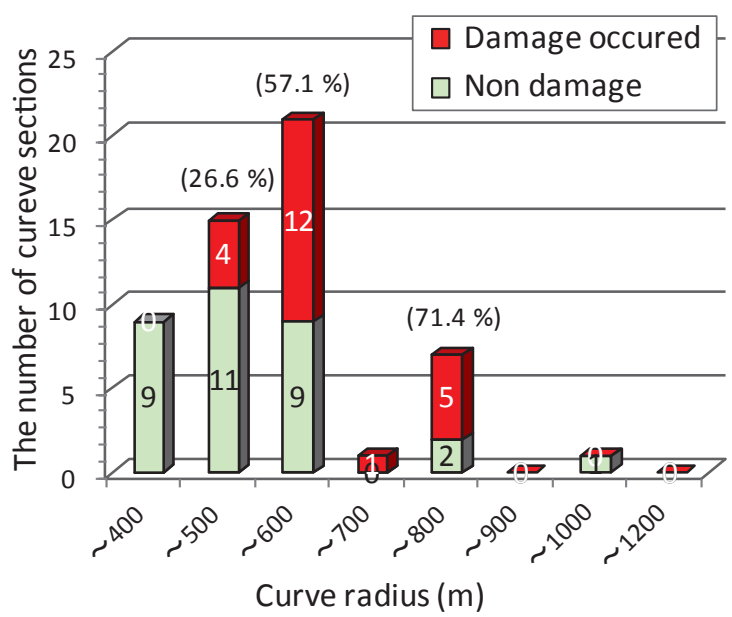

(b) Head hardened rail

Fig. 7 Tendency of the damage to the high rail 
Table 2 The new types of head-hardened rails

\begin{tabular}{|c|c|c|c|c|c|c|}
\hline Rail steel grade & A & B & $\mathrm{C}$ & $\mathrm{D}$ & As rolled & НН340 \\
\hline Concept & \multicolumn{3}{|c|}{ Balancing wear and fatigue } & $\begin{array}{l}\text { Restraining } \\
\text { the plastic } \\
\text { deformation }\end{array}$ & - & - \\
\hline Amount of carbon & $0.63-0.75 \%$ & $0.72-0.82 \%$ & $0.72-0.82 \%$ & $0.72-0.82 \%$ & $0.63-0.75 \%$ & $0.72-0.82 \%$ \\
\hline Hardness & $300 \mathrm{HB}$ & $285 \mathrm{HB}$ & $315 \mathrm{HB}$ & $370 \mathrm{HB}$ & $270 \mathrm{HB}$ & $340 \mathrm{HB}$ \\
\hline JIS & - & - & - & - & E 1101 & E 1120 \\
\hline
\end{tabular}
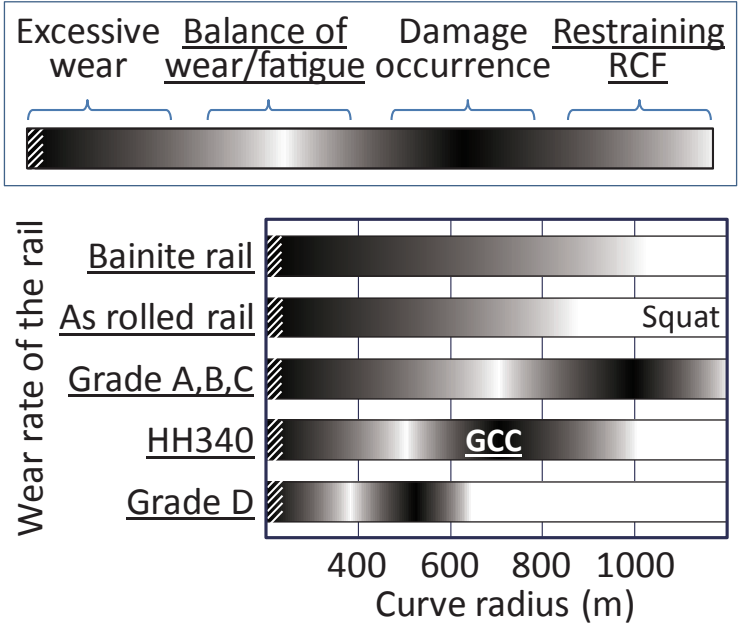

Fig. 8 Concept of the new types of head hardened rails

rail steel grades with the strength between the as rolled rail and the HH340 rail. They aim at balancing wear and fatigue to control the accumulation of the RCF. Their hardness is $300 \mathrm{HB}$ for rail steel grade A, $285 \mathrm{HB}$ for rail steel grade B, and 315HB for rail steel grade C. Another rail is produced according to the second concept. There is only one rail steel grade with the strength higher than the HH340 rail. It aims at restraining the plastic deformation leading to the RCF accumulation by increasing material strength. The rail of this concept is at rail steel grade D (370HB). Table 2 shows the specifications of the new types of head hardened rails developed. All types have a pearlitic microstructure.

Figure 8 shows the concept of the new types of head hardened rails and the wear - damage outbreak situation of the current rail. Regarding the as rolled rail, the incidence of the damage in curve sections is low, but wear progress is large. On the other hand, the HH340 rail has a high damage incidence in curve sections with a radius of $600 \mathrm{~m}$ to $800 \mathrm{~m}$. The new types of head hardened rails are intended to counterbalance the disadvantages brought about by these problems. Authors confirm their performance in an installation examination. In addition, Bainite rail is a Japanese rail which was developed to control squat occurring on a straight track [6].

\section{Performance confirmation examination}

Authors carried out a performance confirmation exami- nation of the new types of head hardened rails installed in commercial tracks with curve radii of $600 \mathrm{~m}$ and $800 \mathrm{~m}$. In the past, those tracks experienced the GCC occurrence in the high rail. In addition, in each examination section, the HH340 rail and as rolled rail were installed at the same time for easy comparison.

\subsection{Curve radius of $800 \mathrm{~m}$ (Grade A, D, HH340)}

So far the investigation has been carried out at certain intervals until the cumulative passing tonnage reaches 170 MGT. Figure 9 shows the track layout and the morphology of each rail surface.

As a result of the observation of the rail surface and the magnetic particle testing, the GCC has not been yet confirmed at the railhead surface in any of the rail steel grades. The cumulative passing tonnage until the rail failure caused by the GCC was empirically $200-400 \mathrm{MGT}$ in the past. Judging from the data of the rail flaw detection car, most of the damage seemed to come up after the cumulative passing tonnage reached about 200 MGT. Hence, authors need to continue the performance confirmation examination until the GCC-resistance characteristics depending on the rail steel grade are clarified.

\subsection{Curve radius of $600 \mathrm{~m}$ (Grade A, B, C, As rolled rail)}

So far the investigation has been carried out at certain intervals until the cumulative passing tonnage reaches 40 MGT. Figure 10 shows the track layout and the morphology of each rail surface. The head checks begin to form in various rails, but the GCC does not form because the cumulative passing tonnage is low. In addition, the length and the distance between each head check are different depending on the hardness, and this result resembles that of the past study [7].

\subsection{Transition of wear}

Authors measured the cross-section of the rails of all examination sections by a mini-prof to grasp the tendency of the wear of various rails. The wear volume of 45 degrees that was calculated from the rail head profile changed according to the concept (see Fig. 11). The quantity of the wear of the Grade A, B, C rails fell between the as rolled rail and the HH340 rail, and, in the Grade D rail, the quantity of wear was more restrained than the HH340 rail. 

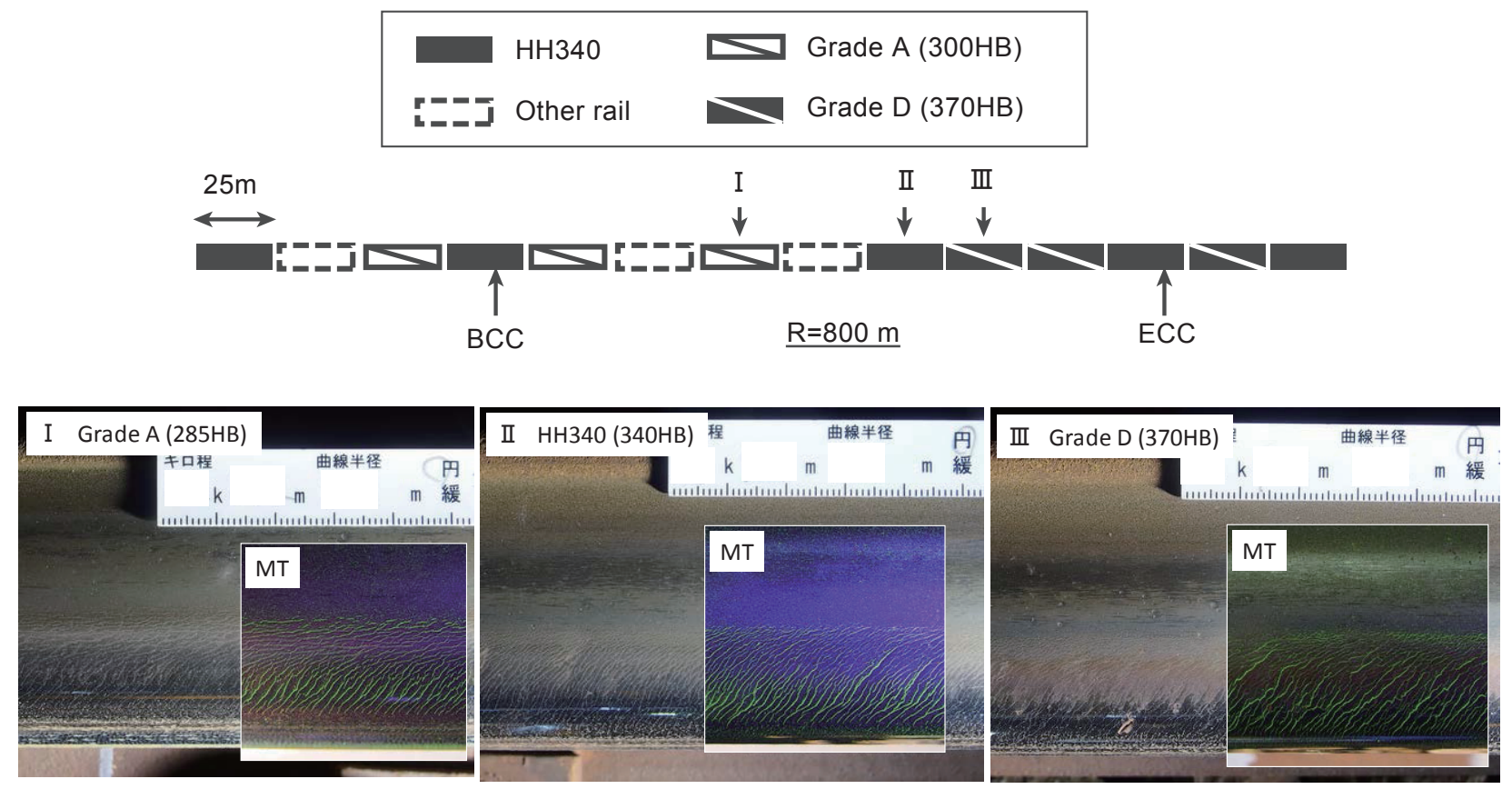

Fig. 9 Track layout and morphology of each rail surface (Curve radius of $800 \mathrm{~m}$ )

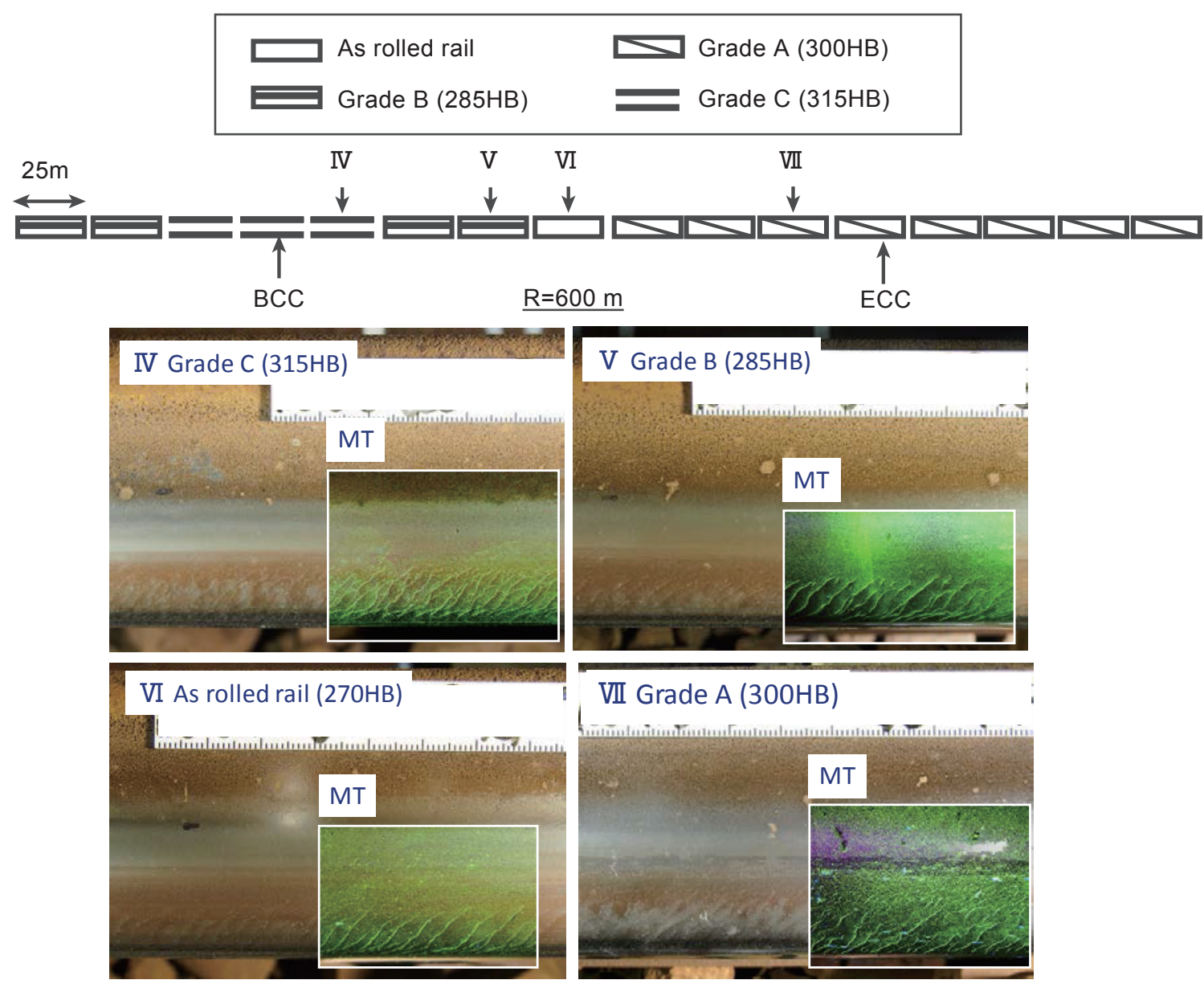

Fig. 10 Track layout and morphology of each rail surface (Curve radius of $600 \mathrm{~m}$ ) 


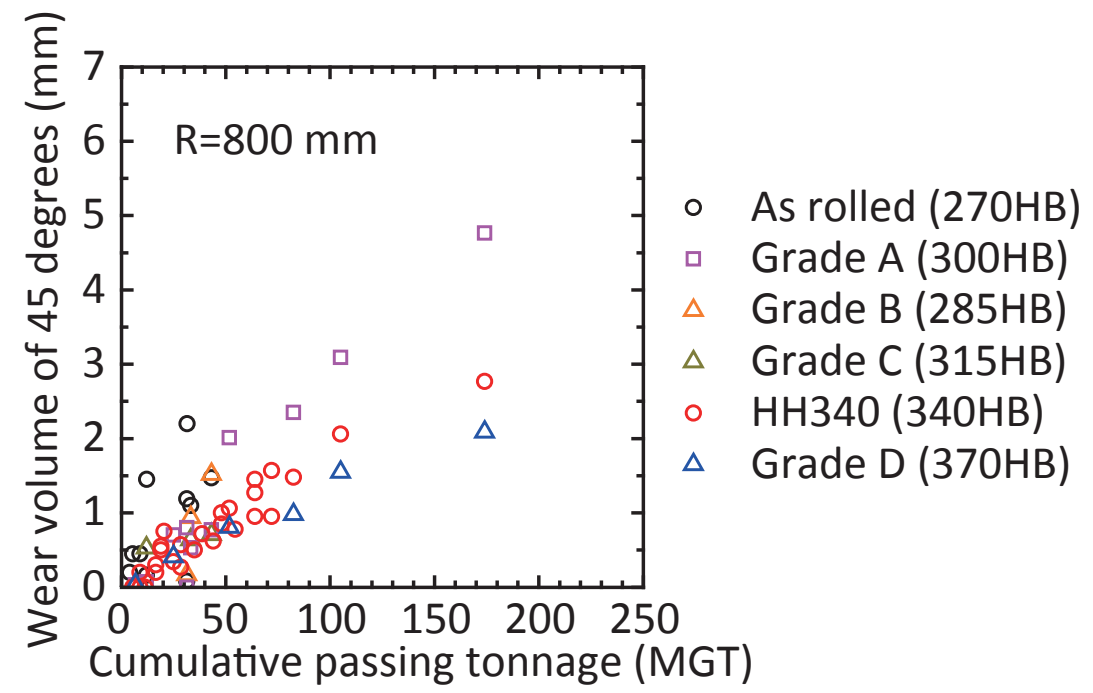

Fig. 11 The wear volume of $\mathbf{4 5}$ degrees and cumulative passing tonnage

\section{Summary and outlook}

The head hardened rail (HH340 rail, 340HB) which is harder than the normal rail (as rolled rail, 270HB) is used for the high rail in the curve sections to reduce the wear.

The HH340 rail shows a wear resistance effect. However, in late years, the GCC occurs to the HH340 rail of the high rail in curve sections with a curve radius of $600 \mathrm{~m}$ to $800 \mathrm{~m}$.

Therefore, authors developed new types of head hardened rail for the purpose of preventing rail failure and reducing track maintenance work. In addition, authors show the result of the continuing examinations on their installation.

(1) Regarding the damage of the high rail in curve sections, it is classified roughly into the head checks and the GCC. Generally, the head checks stop growing at a certain depth. On the other hand, the GCC progresses to a horizontal split head and transverse cracking, and finally reaches rail failure.

(2) The GCC resembles the head check closely in the form at its initial stage, but when the crack progresses, it assumes an appearance characterized by chevronshaped cracks at the corners and dark spots formed around them.

(3) The depth of the positions where the transverse cracking initiates the brittle fracture does not vary from one position to another as far as our investigations are concerned. And it is shallow, i.e., about $2 / 3$ the depth usually observed in sqauts. Therefore, it is thought that the time before reaching rail failure is shorter than that the squat in the straight line section takes.

(4) As a result of the analysis of the damage incidence of the high rail in curve sections, as an overall tendency, the damage occurrence rate of the as rolled rail $(270 \mathrm{HB})$ was lower than that of the HH340 rail (340HB). Particularly at a curve of $600 \mathrm{~m}$ in radius, the as rolled rail had $23 \%$, whereas the HH340 rail had $56 \%$. This tendency is attributable to conditions in which the wear of the As rolled rail tends to be promoted due to its low hardness, while the RCF can be prevented from accumulating.
(5) The new types of head hardened rails cover four rail steel grades under two types of concepts for the purpose of restraining the GCC.

(6) Authors carried out a performance confirmation examination of the new types of head hardened rails installed in commercial tracks with curve radii of $600 \mathrm{~m}$ and $800 \mathrm{~m}$.

(7) As a result of the observation of the rail surface and the magnetic particle testing, the GCC has not been yet confirmed at the railhead surface in any of the rail steel grades due to the small passing tonnage experienced.

(8) The cumulative passing tonnage until the rail failure caused by the GCC was empirically 200-400 MGT in the past. Judging from the data of the rail flaw detection car, most of the damage seemed to come up after the cumulative passing tonnage reached about 200 MGT. Hence, authors need to continue the performance confirmation examination until the GCC-resistance characteristics depending on the rail steel grade are clarified.

\section{References}

[1] Japanese Industrial Standards (JIS), JIS E 1120 Head hardened rails, 2007.

[2] R. Stock, R. Pippan, "RCF and wear in theory and practice - the influence of rail grade on Wear and RCF," Proceedings of the 8th International Conference of Contact Mechanics and wear of Rail/Wheel Systems (CM2009), Firenze, Italy, 2009, pp.579-588.

[3] R. Heyder, T. Hempe, "Maintenance strategies and material concept to control rolling contact fatigue of rails," Proceedings of the 8th International Conference of Contact Mechanics and wear of Rail/Wheel Systems (CM2009), Firenze, Italy, 2009, pp.607-616.

[4] D. Szablewski, J. LoPresti, D. Sammon, "Premium Rail Testing at FAST," Technology Digest TD-13-016, 2013.

[5] M. Takikawa et al., The Journal of Japan Railway Civil Engineering Association, 2006, Vol.44, No.9, (In 
Japanese).

[6] Y. Sato, M. Tatsumi, K. Kashiwaya, M. Ueda, H. Yokoyama, "Development of Anti-Darkspot Bainitic Steel Rail,” $Q R$ of RTRI, vol.40, pp.86-91, 1999.

[7] R. Stock, R. Pippan, "Rail grade dependent damage behavior - Characteristics and damage formation hypothesis," Proceedings of the 9th International Conference of Contact Mechanics and wear of Rail/Wheel Systems (CM2012), Chengdu, China, 2012, pp.284-292.

\section{Authors}

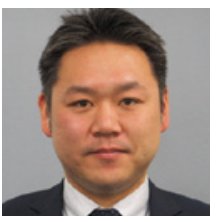

Yoshikazu KANEMATSU

Assistant Senior Researcher, Frictional

Materials Laboratory, Materials Technology Division

Research Areas: Track material analysis and development

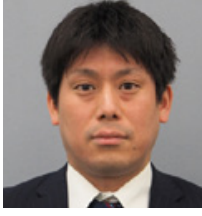

Masahiro TSUIJIE

Assistant Senior Researcher, Track Dynamics Laboratory, Railway Dynamics Division Research Areas: Rail, Wear, Rail defect

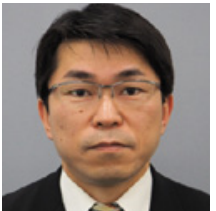

Motohide MATSUI, Ph.D

Senior Chief Researcher, Laboratory Head, Frictional Materials Laboratory, Materials Technology Division

Research Areas: Track material analysis and development 